\title{
Do Cruzado à moratória: o legado do experimento heterodoxo
}

Ivan Salomão*

RESUMO
A trajetória política de José Sarney respondeu por um dos principais motivos de sua
fragilidade quando assumiu a Presidência da República. Inserido no momento histórico
do ocaso do regime militar, o vice-presidente indiretamente eleito enfrentou a
hostilidade popular e a indiferença do establishmet político. Desse modo, Sarney tratou
de fazer do Plano Cruzado e da negociação da dívida externa suas principais bandeiras
políticas. Conquanto fracassadas, ambas as tentativas representam um relevante
aprendizado político, econômico e institucional ao Brasil contemporâneo.
PALAVRAS-CHAVE: José Sarney; Plano Cruzado; Moratória da dívida externa; Nova
República.

\section{RESUMEN}

La carrera política de José Sarney fue de una de las principales razones de su debilidad cuando asumió la presidencia de la Republica. Inserido en el momento histórico de la caída del régimen militar, el vicepresidente electo indirectamente enfrentó la hostilidad popular y la indiferencia de la establishmet político. Por lo tanto, Sarney trató de hacer del Plan Cruzado y de la negociación de la deuda externa de sus principales banderas políticas. Aunque sin éxito, ambos intentos representan un relevante aprendizaje político, económico e institucional para el Brasil contemporáneo.

PALABRAS CLAVE: José Sarney; Plano Cruzado; Moratória de la deuda externa; Nueva Republica.

ABSTRACT
José Sarney's political carrer was responsible for his own weakness when he assumed
the presidency of Republic. Involved in the historic moment of the decline of the
military regime, the vice president faced popular hostility and indifference of the
political establishmet. Thus, Sarney tried to make Cruzado's Plan and the negotiation of
foreign debt his main political causes. Although unsuccessful, both attempts represent a
relevant political, economic and institutional learning to Brazilian contemporary history.
KEYWORDS: José Sarney; Cruzado's Plan; External Debt Moratorium; New
Republic.

\section{Introdução}

O momento histórico e a conjuntura econômica em que José Sarney assumiu a

Presidência da República concorreram diretamente para a perene crise de legitimidade

\footnotetext{
* Professor FCE-UFRGS.
} 
que pairou sobre os cinco anos de seu mandato. O Brasil que emergia após duas décadas do regime militar encarava, além da crise política envolta ao processo de redemocratização, as severas adversidades econômicas representadas pelo colapso externo e, principalmente, a inflação.

Candidato a vice-presidente da chapa vitoriosa na eleição indireta, Sarney carecia não apenas da legitimidade que não lhe fora conferida pelas urnas, mas principalmente daquela decorrente de sua condição de ex-presidente do PDS, partido de sustentação do regime autoritário ao qual o novo governo oferecera oposição ferrenha.

Abandonado pelas lideranças políticas, Sarney procurou nas ruas o apoio indispensável a um governante deslegitimado. O lançamento de medidas econômicas de repercussão popular foi a maneira pela qual o presidente tentou granjear popularidade ao seu governo. A primeira e mais conhecida delas foi o lançamento do Plano Cruzado, em fevereiro de 1986. Exitoso em seu objetivo político, o sucesso inicial do plano heterodoxo de estabilização elevou Sarney à efêmera condição de estadista durante todo o ano de 1986, período em que atingiu os mais elevados níveis de aprovação já auferidos por um presidente brasileiro até então (SAAB, 1987).

Após a sucumbência do plano, o presidente encontrou nos obstáculos impostos pelos credores da dívida externa sua nova causa interna. Com efeito, o grau de deterioração das contas do balanço de pagamentos a que se chegara no início dos anos 1980 não havia encontrado paralelo na história republicana brasileira. A política econômica durante a primeira metade daquela década limitara-se a gerir, da maneira menos onerosa possível, os ônus impostos pela crise internacional.

A negociação da dívida externa sofreu inflexão significativa após a nomeação de Dílson Funaro para o Ministério da Fazenda, em agosto de 1985. O novo ministro passou a recusar peremptoriamente o monitoramento do FMI, o qual sugeria uma política de ajuste recessivo para atenuar os ônus do malsucedido plano de estabilização monetária. Os desdobramentos políticos e econômicos dessa nova postura do governo brasileiro resultaram diretamente na decretação da moratória da dívida externa, em fevereiro de 1987.

A lógica de se arcar com custos tão elevados quanto os decorrentes de uma ruptura externa não careceu de um cálculo político preciso. A esperada retaliação externa não influenciaria a decisão diante da sua necessidade de galgar o apoio da classe 
política e, principalmente, da população. É neste sentido que se justifica a racionalidade política subjacente a medidas heterodoxas de ampla ressonância junto à opinião pública, como foram o Plano Cruzado e a moratória da dívida forânea.

O presente trabalho tem por objetivo resgatar e sistematizar duas das principais medidas heterodoxas da política econômica do governo Sarney (1985-1990) e suas repercussões políticas, econômicas e institucionais. Para tanto, estruturou-se o trabalho em quatro pontos, incluindo esta breve introdução. Na segunda seção, apresentam-se sucintamente as políticas contidas no Plano Cruzado, bem como suas consequências sobre as contas externas do país. Em seguida, expõem-se a situação das contas externas do país e os meandros da negociação com os credores estrangeiros. No ponto seguinte aborda as principais consequências dessas duas de ampla repercussão, seguido, por fim, das considerações finais.

\section{O Plano Cruzado e seus desdobramentos sobre as contas externas}

A economia brasileira foi incisivamente afetada pelas medidas contidas no Plano de Estabilização Econômica de fevereiro de 1986. Delegam-se à tentativa heterodoxa de se eliminar a correção monetária, responsabilizada à época pela crescente elevação dos preços, desdobramentos relevantes sobre as contas externas. Foge do escopo deste trabalho a discussão detalhada das teorias concernentes à inflação inercial, bem como a apreciação detida dos ingredientes técnicos do plano, de sua condução e dos motivos que o levaram ao fracasso. Após uma breve apresentação geral daquele que seria o primeiro choque antiinflacionário da Nova República, analisar-se-ão as consequências do Plano Cruzado sobre a conjuntura econômica do país.

O contexto político em que tomou posse o primeiro governo civil após duas décadas de ditadura em muito influenciou a opção pelo choque heterodoxo ${ }^{1}$. A necessidade de se eliminar sentimentos nostálgicos em relação ao outrora popular regime de exceção exigia medidas de impacto imediato e efetivo. A esperança subjacente à derrocada do governo autoritário fomentou, no imaginário social, a expectativa de que o retorno à democracia bastava por si só para extinguir todos os

\footnotetext{
${ }^{1}$ Sabe-se que, além do congelamento de preços, o governo dispunha de pelo menos outras três opções: o choque ortodoxo, a moeda indexada e o pacto social, propostos por economistas ligados à FGV-RJ, à PUC-RJ e à Unicamp, respectivamente. Para os bastidores do Plano Cruzado, ver, por exemplo, Sarney (2006), Solnik (1988) e Sardemberg (1987).
} 
males que acometiam a sociedade brasileira, incluindo aí o inimigo público número um daquele momento: a inflação.

A equipe econômica do Ministério do Planejamento diagnosticou na inércia inflacionária - fenômeno pelo qual a "memória" da inflação anterior é propagada para os preços, salários e ativos financeiros correntes através de mecanismos de indexação ${ }^{2}-$ o principal motivo da escalada descontrolada do custo de vida. As medidas centrais do Plano Cruzado podem ser sintetizadas em quatro pontos: (1) reforma monetária e congelamento; (2) desindexação; (3) alteração nos índice de preços; e (4) política salarial. O primeiro estabelecia o cruzado como o novo padrão monetário, em substituição ao cruzeiro. O principal mote do plano, contudo, determinava que os preços de todos os produtos e da taxa de câmbio ficariam congelado a partir do último dia de fevereiro. A figura do "fiscal do presidente", cidadãos que se auto-incumbiram de vigiar e denunciar estabelecimentos comerciais que remarcassem seus preços, conferiu grande popularidade à figura de José Sarney.

O segundo ponto consistia em substituir as antigas Obrigações Reajustáveis do Tesouro Nacional (ORTN) pelas novas Obrigações do Tesouro Nacional (OTN), que continuavam a ser denominadas na antiga moeda, desvalorizadas diariamente, porém, a uma taxa correspondente à inflação apurada entre dezembro de 1985 e fevereiro de 1986. Esta conversão tinha por objetivo minimizar o problema da expectativa de inflação embutida nas obrigações financeiras. A terceira medida propunha o deslocamento do período de apuração do índice de preços oficial (IPCA) com o objetivo de eliminar a contaminação do índice pela inflação de fevereiro. E a última grande proposta do plano referia-se aos salários, os quais também deveriam permanecer congelados após o reajuste inicial de $8 \%$ concedidos aos assalariados em geral e de $16 \%$ para o salário mínimo. Com o intuito de não se desgastar perante a classe trabalhadora, justamente aquela da qual o governo pretendia se aproximar, foi criado o "gatilho salarial", instrumento que garantiria a correção imediata dos salários sempre que a inflação acumulasse 20\% (CASTRO, 2005).

O retumbante sucesso inicial do Plano Cruzado sugeria o êxito dos objetivos traçados pelo presidente Sarney: o econômico (eliminar a inflação sem recorrer à

\footnotetext{
${ }^{2}$ Camargo e Ramos (1990, p. 10) condicionam uma economia indexada à existência de instrumentos, formais ou informais, que reajustem automaticamente as rendas nominais segundo a ocorrência da inflação. No caso brasileiro, desde os anos 60, três mecanismos de indexação foram formalmente adotados: correção monetária dos ativos financeiros, as minidesvalorizações cambiais e a política salarial.
} 
recessão) e o político (conferir legitimidade ao governo). A inflação praticamente zerou entre abril e julho, permanecendo abaixo dos $2 \%$ até outubro (Tabela 1). Já a taxa de desemprego caiu para valores inferiores a $4 \%$ antes ainda do mês de julho. Os reveses fiscais, contudo, não tardaram a surgir. A redução da receita de senhoriagem e o congelamento de algumas tarifas públicas impactaram fortemente as contas públicas.

\section{Tabela 1 - Inflação Mensal (IGP-DI) e Taxa de Desemprego Aberto Brasil, 03/1986-02/1987 (em \%)}

\begin{tabular}{crr}
\hline Mês & IGP-DI & Desemprego \\
\hline $03 / 1986$ & 5,52 & 4,87 \\
$04 / 1986$ & $-0,58$ & 4,57 \\
$05 / 1986$ & 0,32 & 4,47 \\
$06 / 1986$ & 0,53 & 4,16 \\
$07 / 1986$ & 0,63 & 3,99 \\
$08 / 1986$ & 1,33 & 3,85 \\
$09 / 1986$ & 1,09 & 3,57 \\
$10 / 1986$ & 1,39 & 3,24 \\
$11 / 1986$ & 2,46 & 2,90 \\
$12 / 1986$ & 7,56 & 2,57 \\
$01 / 1987$ & 12,04 & 3,49 \\
$02 / 1987$ & 14,11 & 3,64 \\
\hline
\end{tabular}

Fonte: Ipeadata. Acesso em http://www.ipeadata.gov.br/.

A equipe econômica logo detectou os perigos de um superaquecimento da demanda. A inviabilidade política de um descongelamento e a cisão interna entre os técnicos do governo impossibilitaram, contudo, a adoção de medidas de maior alcance. De modo que, em 23 de julho de 1986, lançou-se o chamado "Cruzadinho", um simples pacote fiscal com o objetivo de desaquecer o consumo e financiar um plano de infraestrutura e de metas sociais. O reajuste dos preços proposto no pacote, contudo, foi expurgado do índice oficial de inflação, gerando legítima revolta da população. A medida fracassou por completo, não atendendo nem às necessidades de frear a demanda, tampouco às de gerar recursos para as obras. Neste sentido é que Modiano (1992, p. 360) analisa o agravamento da conjuntura ao afirmar que "o segundo período, que vai 
de julho a outubro de 1986, pode ser identificado pela total imobilidade do governo ante o agravamento da escassez de produtos e à deteriorização das contas externas."3

A pressão pelo descongelamento não se fez ausente ao longo de todo o ano de 1986. Havia recomendações tanto de ordem técnica quanto política para que o livre mercado voltasse a determinar o preço das mercadorias, serviços, salários e da taxa de câmbio. Na prática, porém, tornaram-se efetivamente passíveis de controle os preços dos setores oligopolizados e de grandes empresas, justamente aqueles que exercem maior poder de barganha junto às autoridades públicas ${ }^{4}$. A necessidade de usufruir do bônus político trazido pela estabilidade monetária incitou o presidente a oferecer uma sobrevida artificial ao congelamento, preterindo as advertências dos burocratas, acadêmicos e empresários em benefício da popularidade fugaz.

O presidente da República já demonstrava interferir em questões técnicas de acordo com a conveniência política. Por ocasião da formulação do pacote fiscal do Cruzadinho, Sayad revela a "sensibilidade popular" de Sarney: "era para aumentar o preço da gasolina em $3 \mathrm{x}$, ele cortava para $\mathrm{x}[\ldots]$. A gente incluía também aumentos de telefone, de energia elétrica, era uma vastidão de produtos. E o presidente cortou tudo, achou que ia ser muito ruim, muito pouco simpático, pouco popular." (apud SOLNIK, 1988, p. 30).

A deterioração dos fundamentos macroeconômicos ao longo do segundo semestre do ano fomentou o lançamento, em 21 de novembro, do chamado "Cruzado II”, um novo pacote fiscal que tinha por objetivo aumentar a arrecadação em $4 \%$ do PIB. A remarcação dos preços de determinados produtos aos consumidores finais e de algumas tarifas públicas serviram, na prática, como aval para que o congelamento fosse finalmente abolido. Em janeiro de 1987, o gatilho salarial foi disparado, o que aumentou ainda mais a descrença dos agentes econômicos no governo, levando à extinção oficial do plano no mês subsequente.

De acordo com os próprios formuladores do plano, erros de concepção e de condução foram decisivos para o seu fracasso, a saber: (1) o diagnóstico de que a

\footnotetext{
${ }^{3}$ Modiano (1992, p. 363) reforça ainda mais a inanição do governo após o lançamento do Cruzadinho ao afirmar que "de agosto a 15 de novembro, a política econômica ficou paralisada: todos os esforços do governo foram concentrados nas eleições para governadores e para a Assembleia Constituinte."

${ }^{4}$ Detalhe menor, mas de eloquente simbologia, a tarefa de anunciar o fim do descongelamento não coube aos gestores da política econômica, mas sim aos presidentes da CNI e da FIESP (CAMARGO; RAMOS, 1990, p. 35).
} 
inflação era puramente inercial estava equivocado; (2) a inconveniência técnica dos abonos salariais concedidos antes do congelamento; (3) a condução das políticas monetária e fiscal foi menos austera do que o necessário ${ }^{5}$; (4) o período do congelamento de preços foi demasiadamente longo, tendo sido os preços mantidos em seus níveis correntes, distorcendo ainda mais os preços relativos; (5) o gatilho salarial indexou ainda mais a economia; (6) a manutenção do câmbio fixo contribuiu para a deterioração das contas externas; e (7) a defasagem dos preços públicos agravou a situação fiscal do governo (CASTRO, 2005, p. 128).

Em relação aos impactos do plano sobre o balanço de pagamentos em si, pode-se afirmar que os resultados verificados ao longo daquele ano de fato surpreenderam os técnicos do governo, uma vez que o início de 1986 oferecia condições externas vantajosas ao lançamento de um plano heterodoxo de estabilização (Tabela 2). A conjuntura internacional apresentava-se favorável em diversos aspectos: o preço do barril de petróleo havia sofrido queda vertiginosa (de US\$ 27 em novembro, para menos de US\$ 10, em março); as taxas de juros nas praças financeiras da Europa e dos Estados Unidos haviam retornado a patamares pré-crise; o valor do dólar vis-à-vis a moeda brasileira mantinha sua rota descendente; e, por fim, os países industrializados emitiam sinais de que manteriam os expressivos resultados referentes ao crescimento do PIB que vinham apresentando havia três anos (PRESSER, 1986, p. 271). Os efeitos colaterais da estabilização, porém, neutralizariam as oportunidades do cenário externo em poucos meses.

\footnotetext{
${ }^{5}$ A posição acessória destes instrumentos é ressaltada por Modiano (1992, p. 359 e 362): "o Plano Cruzado não estabeleceu regras ou metas para as políticas monetária e fiscal para complementar o programa de estabilização [...], sendo relegada ao discernimento dos responsáveis pela política econômica." A instrumentalização política da gestão fiscal também se fez presente pois, conforme destaca o autor "quando se verificou aumento da receita, este foi mais do que neutralizado pelo aumento de gastos, fruto da necessidade de se sustentar o congelamento de preços e, portanto, contribuir para a vitória do PMDB nas eleições de novembro."
} 


\section{Tabela 2 - Transações Correntes, Conta Capital, Saldo do Balanço de Pagamentos}

e Dívida Externa - Brasil, 01/1986-03/1987 (em milhões de US\$)

\begin{tabular}{lrrrr}
\hline Trimestre & $\begin{array}{c}\text { Transações } \\
\text { Correntes }\end{array}$ & $\begin{array}{c}\text { Conta } \\
\text { Capital }\end{array}$ & $\begin{array}{c}\text { Balanço de } \\
\text { Pagamentos }\end{array}$ & $\begin{array}{c}\text { Dívida } \\
\text { Externa }\end{array}$ \\
\hline $1^{\circ}$ tri/1986 & $-719,21$ & $-3,95$ & $-511,20$ & $98.120,10$ \\
$2^{\circ}$ tri $/ 1986$ & 278,65 & 216,80 & $-332,60$ & $99.622,30$ \\
$3^{\circ}$ tri $/ 1986$ & $-1.026,80$ & 282,09 & $-859,80$ & $100.895,60$ \\
$4^{\circ}$ tri $/ 1986$ & $-3.855,89$ & 936,60 & $-2.132,10$ & $101.758,70$ \\
$1^{\circ}$ tri $/ 1987$ & $-2.522,95$ & 872,69 & $-1.302,00$ & $104.377,40$ \\
\hline
\end{tabular}

Fonte: Para os dados referentes às transações correntes e à dívida externa, Ipeadata. Acesso em http://www.ipeadata.gov.br/. Para os demais, Banco Central do Brasil. Acesso em http://www.bcb.gov.br/.

Os reflexos do congelamento de preços sobre a balança comercial já se faziam sentir ao final do primeiro semestre de 1986. O desequilíbrio entre a demanda já aquecida e a oferta interna gerado pela estabilidade monetária e pela quebra de safra agrícola do final do ano anterior resultou em um aumento abrupto das importações de bens de consumo não-duráveis e de alimentos ${ }^{6}$. Por outro lado, a fixação da taxa de câmbio também refletiu negativamente sobre as exportações em dois aspectos. Em primeiro lugar, a apreciação nominal do cruzado frente às moedas estrangeiras minou a competitividade dos produtos semi-manufaturados exportados pelo Brasil. Além disso, os exportadores brasileiros passaram a especular com seus estoques a fim de pressionar o governo a reequilibrar o câmbio através de uma maxidesvalorização. Em outubro, setes meses após o lançamento do plano, o Ministério da Fazenda depreciou o cruzado em 1,81\% em relação ao dólar, medida que se mostrou ineficiente para conter a deterioração dos saldos da balança comercial (tabela 3 ).

\footnotetext{
${ }^{6} \mathrm{Na}$ esteira do anedótico caso da escassez de carne bovina, Nepomuceno (1990, p. 131) relembra que em "determinados momentos, a mesa do brasileiro médio se assemelhava à imagem que normalmente era dada à mesa dos grandes nababos: quase todos os produtos, da carne ao feijão, eram importados."
} 


\section{Tabela 3 - Exportações, Importações e Saldo da Balança Comercial (FOB) Brasil, 03/1986-02/1987 (em milhões de US\$)}

\begin{tabular}{rrrr}
\hline Mês & Exportações & Importações & $\begin{array}{c}\text { Balança } \\
\text { Comercial }\end{array}$ \\
\hline $03 / 1986$ & $2.156,00$ & $1.021,10$ & $1.134,90$ \\
$04 / 1986$ & $2.171,00$ & 880,40 & $1.290,60$ \\
$05 / 1986$ & $2.289,00$ & 951,30 & $1.337,70$ \\
$06 / 1986$ & $1.999,00$ & 928,70 & $1.070,30$ \\
$07 / 1986$ & $2.204,00$ & $1.198,90$ & $1.005,10$ \\
$08 / 1986$ & $2.094,00$ & $1.149,00$ & 945,00 \\
$09 / 1986$ & $1.847,00$ & $1.312,70$ & 534,30 \\
$10 / 1986$ & $1.337,00$ & $1.419,80$ & $-82,80$ \\
$11 / 1986$ & $1.270,00$ & $1.308,10$ & $-38,10$ \\
$12 / 1986$ & $1.325,00$ & $1.542,70$ & $-217,70$ \\
$01 / 1987$ & $1.264,00$ & $1.299,40$ & $-35,40$ \\
$02 / 1987$ & $1.452,00$ & $1.131,70$ & 320,30 \\
\hline
\end{tabular}

Fonte: Ipeadata. Acesso em http://www.ipeadata.gov.br/.

Paralelamente à diminuição do saldo comercial, os déficits em que incorria a balança de serviços aumentavam significativamente desde 1980 em função da pósfixação dos contratos de empréstimos estrangeiros. Entre 1983 e 1986, o Brasil remeteu ao exterior, em termos líquidos, US\$ 34 bilhões, sendo que, somente neste último ano, pagou-se aos bancos a quantia de US\$ 6 bilhões (BATISTA JÚNIOR, 1988, p. 36). Este valor chegou a representar quase a metade das exportações do país ou aproximadamente $5 \%$ do $\mathrm{PIB}^{7}$. Ultraja ainda mais o cenário se levado em consideração, conforme ressaltam Camargo e Ramos (1990, p. 14), o fato de que parcela relevante destes esforços foi alcançada através do achatamento dos salários reais, uma vez que o período de reajuste dos mesmos foi sempre superior ao das outras rendas na economia (LAGO, 1988, p. 13).

É neste sentido que se pode afirmar que as contas externas do Brasil haviam adentrado um ciclo vicioso, uma vez que grande parte da elevação do déficit em transações correntes a partir de 1979 - e a quase totalidade desse aumento a partir de

\footnotetext{
${ }^{7}$ Outra relação que atuava a favor da moratória brasileira é apontada por Fassy (1986, p. 23), segundo quem, guardadas as incalculáveis diferenças históricas, políticas e econômicas, a Polônia devia valor correspondente a 17\% do seu PIB quando declarou sua moratória. Para o Brasil, esta razão já ultrapassava a marca dos $30 \%$.
} 
1981 - refletia o crescimento exógeno dos encargos da dívida externa (HERMANN, 2005, p. 113).

Tabela 4 - Balança Comercial, Balança de Serviços e Saldo em Transações

Correntes - Brasil, 03/1986-02/1987 (em milhões de US\$)

\begin{tabular}{crrr}
\hline Mês & $\begin{array}{c}\text { Balança } \\
\text { Comercial }\end{array}$ & $\begin{array}{c}\text { Balança de } \\
\text { Serviços }\end{array}$ & $\begin{array}{c}\text { Transações } \\
\text { Correntes }\end{array}$ \\
\hline $03 / 1986$ & $1.134,90$ & $-1.222,60$ & $-79,80$ \\
$04 / 1986$ & $1.290,60$ & $-1.074,90$ & 227,00 \\
$05 / 1986$ & $1.337,70$ & $-911,70$ & 437,90 \\
$06 / 1986$ & $1.070,30$ & $-1.469,00$ & $-386,30$ \\
$07 / 1986$ & $1.005,10$ & $-1.281,40$ & $-264,30$ \\
$08 / 1986$ & 945,00 & $-1.038,60$ & $-89,60$ \\
$09 / 1986$ & 534,30 & $-1.210,90$ & $-672,80$ \\
$10 / 1986$ & $-82,80$ & $-1.152,90$ & $-1.234,30$ \\
$11 / 1986$ & $-38,10$ & $-1.196,20$ & $-1.233,30$ \\
$12 / 1986$ & $-217,70$ & $-1.173,30$ & $-1.388,30$ \\
$01 / 1987$ & $-35,40$ & $-1.521,80$ & $-1.554,50$ \\
$02 / 1987$ & 320,30 & $-818,40$ & $-492,00$ \\
\hline
\end{tabular}

Fonte: Para os dados referentes à Balança de Serviços, Banco Central do Brasil. Acesso em http://www.bcb.gov.br/. Para os demais, Ipeadata. Acesso em http://www.ipeadata.gov.br/.

Os vultosos déficits globais do balanço de pagamentos passaram, assim, a ser neutralizados através do esvaimento da reservas internacionais. A posição de defesa cambial do Banco Central quando do lançamento do Cruzado foi minorada em mais de $50 \%$ em menos de 12 meses, repercutindo de modo crucial na capacidade de importação e de pagamento do serviço da dívida externa (tabela 5). Trata-se, este, de um dos motivos que levaram o governo brasileiro a decretar a moratória. $\mathrm{O}$ menos relevante deles, vale frisar (SALOMÃO, 2010).

Não se pode delegar o rápido esgotamento das reservas cambiais a consequências supostamente inevitáveis do Cruzado, uma vez que o excesso de demanda e a sobrevalorização da moeda nacional já haviam sido diagnosticados ao final do primeiro semestre do ano. Ou seja, não há elementos que ratifiquem a manutenção de tal percurso que não a opção deliberada de se prolongar o congelamento da taxa de câmbio e a recusa consciente de se frear efetivamente a demanda - medidas que 
contrariavam as sugestões técnicas emitidas ainda em julho, durante a reunião em que foi lançado o primeiro pacote corretivo. Pode-se afirmar, portanto, que a necessidade de se decretar a moratória não surpreendeu a equipe econômica do governo, dado que a mesma se anunciara havia meses.

\section{A moratória como instrumento de legitimação política}

Se a opção pelo Plano Cruzado havia se tratado de uma tentativa de conquistar nas urnas a legitimidade que não lhe fora conferidas pelas urnas, conforme assumiu o próprio ex-presidente Sarney (2006), a condução da política referente às contas externas também buscou granjear apoio político que faltava ao governo.

No que concerne ao balanço de pagamentos, a Nova República começou em um momento de rara calmaria devido ao megassuperávit comercial obtido em 1984. Além do consequente acúmulo de reservas cambiais, um cenário internacional otimista conferia ao governo algum fôlego na administração da dívida externa ${ }^{8}$. Naquele ano, os países centrais mantiveram a trajetória de crescimento iniciada em 1983, permitindo que o comércio mundial encerrasse o ano com um crescimento de $12 \%$ em menos de 24 meses (BAER; MACARINI; ANDRADE, 1986).

A despeito dos efeitos deletérios do Cruzado sobre as contas externas, conforme exposto na seção anterior, argumenta-se neste trabalho que a moratória da dívida, decretada em 20 de fevereiro de 1987, também seguiu um cálculo mais político do que propriamente econômico.

Para embasar tal afirmação, deve-se analisar a situação das reservas cambiais no período. Se no decorrer de 1986 a situação externa exigia, de fato, alguma cautela, não se pode negligenciar que o cenário do comércio externo apresentado para o ano de 1987 era extraordinariamente mais otimista se comparado, por exemplo, a 1983, ano em que se registrou o ápice da recessão. Além disso, não se lhe negava ao governo, ainda, outras duas opções: a adoção de medidas restritivas (cambiais, fiscais e/ou monetárias)

\footnotetext{
${ }^{8}$ Pode ser arrolada, ainda, uma série de outros fatores conjunturais que corroboravam as perspectivas favoráveis em relação ao quadro externo: a contínua desvalorização do dólar frente à maioria das moedas; a melhoria dos termos de troca via redução dos preços dos produtos importados; a queda expressiva das taxas de juros internacionais; a redução dos encargos da balança de serviços fatores, entre outras (SAMPAIO JÚNIOR; AFFONSO, 1986).
} 
ou a aceitação das condições impostas pelo FMI em troca de um novo pacote de recursos emergenciais.

Tabela 5 - Reservas Internacionais

Brasil, 03/1986-02/1987 (em milhões de US\$)

\begin{tabular}{cr}
\hline Mês & $\begin{array}{c}\text { Reservas } \\
\text { Internacionais }\end{array}$ \\
\hline $03 / 1986$ & $7.425,00$ \\
$04 / 1986$ & $7.665,00$ \\
$05 / 1986$ & $7.792,00$ \\
$06 / 1986$ & $7.274,00$ \\
$07 / 1986$ & $6.982,00$ \\
$08 / 1986$ & $6.668,00$ \\
$09 / 1986$ & $6.776,00$ \\
$10 / 1986$ & $5.566,00$ \\
$11 / 1986$ & $4.901,00$ \\
$12 / 1986$ & $4.585,00$ \\
$01 / 1987$ & $3.729,00$ \\
$02 / 1987$ & $3.331,00$ \\
\hline
\end{tabular}

Fonte: Ipeadata. Acesso em $\underline{\text { http://www.ipeadata.gov.br/. }}$

Diante dos indícios de que não foram apenas as vicissitudes econômicas que levaram o governo brasileiro a suspender o pagamento dos juros da dívida externa, outros elementos concorrem para elucidar a intencionalidade subjacente a mais essa medida heterodoxa. Conforme argumenta Fonseca (2004, p. 591), "se é difícil encontrar uma racionalidade estritamente econômica para o comportamento do governo, o mesmo não ocorre quando se traz à baila variáveis de natureza política.”

Face às considerações expostas acima, sugere-se, portanto, que o principal legado da experimentação heterodoxa da Nova República foi institucional ${ }^{9}$. O aprendizado político e econômico herdado do governo Sarney permitiu que a economia brasileira passasse a se modernizar a partir do início dos anos 1990, quando da abertura

\footnotetext{
${ }^{9}$ No sentido amplo do termo, referimo-nos às instituições como órgãos, políticas públicas e discurso. Baseamo-nos na concepção de Zysman (1994), para quem as instituições são fundamentais na reconstrução histórica porque moldam experiências nacionais e regionais concretas, possibilitando diferentes conformações históricas.
} 
comercial e do plano de estabilização monetária que finalmente viria a derrotar a inflação.

A despeito da desilusão causada pelo fim da estabilidade da moeda, não se deve negligenciar o avanço representado pelo Cruzado no combate à inflação, uma vez que seu arcabouço teórico balizou os mesmos técnicos responsáveis pela formulação do Plano Real na década seguinte. Em termos políticos, o plano que durante oito meses garantiu uma tênue trégua entre governo e sociedade, também contribuiu para a guinada na postura dos negociadores brasileiros junto aos credores da dívida externa.

A própria guinada na política econômica patrocinada pelo presidente Sarney no decorrer de seu mandato já sinalizara o amadurecimento por que passava a condução da política pública no país. Antes de completar dois anos de governo, o presidente havia chancelado duas medidas heterodoxas e de esperado apelo popular: o lançamento do Cruzado (1986) e a decretação da moratória da dívida externa (1987). Nos três anos que lhe faltavam, entretanto, o presidente alterou claramente o perfil das políticas implementadas, finalizando seu governo com medidas liberalizantes e com planos convencionais de combate à inflação e ao déficit público.

Além da abertura econômica - a qual, embora tenha se tornado o principal mote do governo Collor, foi iniciada ainda durante a Nova República -, deve-se ressaltar o aprendizado teórico-institucional proporcionado aos economistas que vieram a criar o Plano Real, em 1994. Isso porque se tratou, basicamente, da mesma equipe de técnicos que havia assessorado o ministro João Sayad na pasta do Planejamento do governo Sarney. Economistas ligados à Pontifícia Universidade Católica do Rio de Janeiro (PUC-Rio) aperfeiçoaram a chamada "proposta Larida" de moeda indexada para formularem o plano que, a partir de primeiro de julho de 1994 passou a colocar o Brasil entre as economias com moedas civilizadas (PRADO, 2005).

Em menos de uma década, a história brasileira demonstrou, assim, que não existe atalho. O desenvolvimento econômico só será sustentável quando fruto de ganhos de produtividade, os quais estão, por sua vez, intimamente relacionados a avanços institucionais, não decorrentes, certamente, de almoço grátis.

\section{Considerações finais}


A sequência de fatos históricos que levou José Sarney à Presidência da República responde por parcela significativa da crise de legitimidade que açoitou os cinco anos de seu mandato. As inúmeras aspirações políticas, reprimidas havia duas décadas pelo regime autoritário, terminaram por estreitar ainda mais o já tênue equilíbrio de forças sobre o qual o presidente governou o país. Desamparado pela classe política, Sarney teve que galgar nas ruas o apoio necessário a um presidente carente de credibilidade.

Historicamente ligado a interesses política e economicamente conservadores, se não contava com o apoio da mídia e dos políticos do Sudeste, José Sarney tampouco angariava a antipatia fatal do mercado e da elite econômica do país. De posse deste capital político, o governo pôde experimentar políticas de ampla repercussão popular para tentar granjear nas ruas a falta de legitimidade negada pelas urnas.

Conquanto tenha fracassado, o Plano Cruzado não contrariou os interesses estabelecidos e nem gerou uma crise institucional. A sucumbência do plano e o fracasso da moratória como meio de legitimação política, porém, reforçaram a certeza de que medidas alternativas não lograriam retomar o rumo do desenvolvimento econômico, impelindo o presidente a adotar uma política econômica claramente ortodoxa nos últimos três anos de seu governo.

Se a crise econômica herdada da Nova República entrou para a historiografia como o momento em que se registrou a mais alta inflação estatisticamente documentada no país, não se deve atenuar o legado positivo do primeiro governo civil após duas décadas de regime militar. Ter entregado o mandato ao candidato democraticamente eleito em 1989 na data prevista não é o único predicado que o presidente José Sarney apresenta em sua biografia política. Além de ter contribuído explicitamente para a promulgação da Constituição Federal de 1988, Sarney pode gabar-se de ter ensinado à sociedade brasileira a necessidade do amadurecimento institucional como condição sine qua non ao desenvolvimento de uma nação.

\section{Referências}

BAER, Mônica; MACARINI, José Pedro; ANDRADE, Rogério P. de. A performance em 1985 e o contexto favorável ao Plano Cruzado. In: CARNEIRO, Ricardo (org.). Política econômica da Nova República. Rio de Janeiro: Paz e Terra, 1986. 
BANCO CENTRAL DO BRASIL. Câmbio e Capitais Internacionais. Disponível em: http://www.bcb.gov.br. Acesso em novembro de 2015.

BATISTA JÚNIOR, Paulo N. Da crise internacional à moratória brasileira. Rio de Janeiro: Paz e Terra, 1988.

CASTRO, Lavínia B. de. Esperança, Frustração e Aprendizado: a História da Nova República (1985-1989). In: GIAMBIAGI, Fabio et al. (orgs.). Economia Brasileira Contemporânea. Rio de Janeiro: Campus-Elsevier, 2005.

CAMARGO, José Márcio; RAMOS, Carlos Alberto. A Revolução indesejada: o Plano Cruzado e o mercado de trabalho. Rio de Janeiro: Campus, 1988.

FASSY, Amaury. Brasil: do FMI ao caos. São Paulo: Global, 1986.

FONSECA, Pedro Cezar D. Legitimidade e Credibilidade: Impasses da Política Econômica do Governo Goulart. Estudos Econômicos, São Paulo, v. 34, n. 3, p. 587622, Jul./Set. 2004.

HERMANN, Jennifer. Auge e declínio do modelo de crescimento com endividamento: o II PND e a crise da dívida externa. In: GIAMBIAGI, Fabio et al (org.). Economia Brasileira Contemporânea. Rio de Janeiro: Campus-Elsevier, 2005.

INSTITUTO DE PESQUISA ECONÔMICA APLICADA. Ipeadata macroeconômico. Disponível em: http://www.ipeadata.gov.br/. Acesso em novembro de 2015.

LAGO, Luiz A. C. do. A suspensão do pagamento dos juros da dívida externa. In: BATISTA JÚNIOR, Paulo N. (org.). Novos ensaios sobre o setor externo da economia brasileira. Rio de Janeiro: FGV-IBRE, 1988.

MODIANO, Eduardo M. A ópera dos três cruzados. In: ABREU, Marcelo de P. (org.). A ordem do progresso. Cem anos de política econômica republicana. Rio de Janeiro: Campus, 1992.

NEPOMUCENO, Eric. O outro lado da moeda: histórias ocultas do Cruzado e da moratória. São Paulo: Siciliano, 1990.

PRADO, Maria Clara R. M. A real história do Real. São Paulo: Record, 2005. 
PRESSER, Mário F. A renegociação da dívida externa na Nova República. In: CARNEIRO, Ricardo (org.). Política econômica da Nova República. Rio de Janeiro: Paz e Terra, 1986.

SALOMÃO, Ivan C. Arroubos econômicos, legitimação política: uma análise da moratória da dívida externa de 1987. 2010. Dissertação de mestrado. Universidade Federal do Rio Grande do Sul, Porto Alegre.

SAMPAIO JÚNIOR, Plínio de A.; AFFONSO, Rui. A transição inconclusa. In: KOUTZII, Flavio (org.). Nova República: um balanço. Porto Alegre: L\&PM, 1986.

SARDEMBERG, Carlos Alberto. Aventura e agonia nos bastidores do Cruzado. São Paulo: Companhia das Letras, 1987.

SAAB, Paulo. A eleição do Cruzado. São Paulo: Global, 1987.

SARNEY, José. Vinte anos do Plano Cruzado. Brasília: Senado Federal, 2006.

SOLNIK, Alex. Os pais do Cruzado contam por que não deu certo. São Paulo: L\&PM, 1987.

ZYSMAN, John. How institutions create historically rooted trajectories of growth. Industrial and corporate change, v. 3, n. 1, p. 243-283, 1994. 